\title{
Key Factors That Influence Sustainability of Community Based Advocacy Groups After Phaseout of Donor Support
}

\author{
William Kholongo ${ }^{1,}$, Edward Lambert ${ }^{1}$, Emmanuel Kaunda $^{2}$, Sam Katengeza $^{2}$, Anthony Malunga ${ }^{3}$ \\ ${ }^{1}$ School of Business and Economics, Atlantic International University, Honolulu, USA \\ ${ }^{2}$ Faculty of Development Studies, Lilongwe University of Agriculture and Natural Resources, Lilongwe, Malawi \\ ${ }^{3}$ Research Unit, Generation Institute of Gender and Development, Lilongwe, Malawi
}

Email address:

wkholongo@yahoo.com (W. Kholongo), edward@aiu.edu (E. Lambert), ekaunda@yahoo.com (E. Kaunda), samkatengeza@gmail.com (S. Katengeza), ajmalunga@gmail.com (A. Malunga)

*Corresponding author

\section{To cite this article:}

William Kholongo, Edward Lambert, Emmanuel Kaunda, Sam Katengeza, Anthony Malunga. Key Factors That Influence Sustainability of Community Based Advocacy Groups After Phaseout of Donor Support. International Journal of Sustainable Development Research. Vol. 6, No. 4, 2020, pp. 73-79. doi: 10.11648/j.ijsdr.20200604.13

Received: December 7, 2020; Accepted: December 15, 2020; Published: December 25, 2020

\begin{abstract}
It is the wish of every stakeholder to see that donor supported structures such as community-based advocacy groups (CBAGs) continue to operate beyond donor support. Various studies show that donor-initiated structures which are often instituted at huge costs experience difficulties with regards to sustainability. This is because such structures reportedly cease to operate after their initial funding runs out resulting into wastage of human and financial resources that could have been invested effectively. However, there is dearth of information regarding the extent to which donor-initiated advocacy groups continue to serve the grassroots, years after phasing out of the donor support. The present study investigated the sustainability of CBAGs, taking a case of advocacy groups initiated and supported by DanChurchAid (DCA) in Malawi. Specifically, the study identified key factors that influence continued operation of CBAGs after years of donor cessation. A combination of quantitative and qualitative approaches was used to collect data from 226 respondents and 16 CBAGs sampled from Karonga, Dowa, Lilongwe, Mwanza and Neno districts from May to June 2020. Secondary data provided preliminary information and cross-validation of information. Descriptive statistics, logit regression and Critical Content Analysis were used to analyze the data. The study identified nine factors that are essential for continued operation of CBAGs namely age of the respondent, marital status of respondent, responsiveness of duty bearers, availability of basic systems and procedures, unity among members, community contribution, linkages and networking, fundraising skills, and availability of exit strategy. It was also noted that need to end corruption, increased prevalence of community problems, and expectation for future benefits were key motivators for members to continue serving in the CBAGs, years after donor support. The study recommends the need to encourage supporting organisations to develop exit strategies which would help to concretize the phasing out plan for supporting the CBAGs. Donors and well-wishers should consider investing in the weak institutional areas of the CBAGs such as organization registration, fundraising and organization systems and procedures which are critical to the institutionalization of the CBAGs. Finally, supporting organisations should design integrated advocacy interventions that achieves advocacy agenda without compromising the personal needs of the CBAGs members. This would require supporting the members with livelihoods activities which will in turn offer immediate needs as the members pursue advocacy work.
\end{abstract}

Keywords: Sustainability, Community Based Advocacy Groups, Advocacy Work, Enabling Factors, Motivating Factors

\section{Introduction}

Community based organisations (CBOs) are increasingly becoming essential in the delivery of services at community level. CBOs are usually locally formed, locally staffed, and their actions are specific to the location they operate in. They exist in various forms, such as voluntary member associations, interest groups, social service agencies, social movement organizations and advocacy groups [1]. However, 
this research focused on $\mathrm{CBO}$ that are classified as community - based advocacy groups (CBAGs), whose definition was provided by CIVICUS 2018. CBAGs are defined as grassroots activists, protests, social movements, CBOs/FBOs, networks, voluntary groups, which are informal in nature responsible for holding local government accountable [2]. They ensure emphatic and vigorous, functioning (speaking, acting, writing) with minimum conflict of interest, on behalf of the sincerely perceived interests of a person or group, with an aim of promoting, protecting, and defending the welfare of, and justice for, either individuals or group of people at community level [3]. CBAGs play an important role in the development of political and social systems, advocation of policy changes and intensification of broad-based awareness about issues adversely impacting poor people. Their roles have become more significant and relevant particularly with the adoption of decentralization policy in 1998. The policy promotes for creation of democratic environment and institutions at the local level, which facilitates the participation of the grassroots in local decision-making processes (Government of Malawi, [4]. For this reason, CABGs are considered as important local structures for allowing local communities to participate in local decision making and hold local government accountable for actions taken in the exercise of delegated functions, powers, and resources [5].

When the CBAGs are initiated and supported, the expectation by donors and stakeholders is that the CBAGs would continue to operate and produce sustainable benefits and impacts on the population beyond donor support [6]. This is in reference to Okun, $M$ who defined sustainability as continued operation and maintenance of project structures, continued flow of net benefits and continued community participation after major assistance from a donor has been completed/withdrawn [7]. Therein, stakeholders expect CBAGs to make sustained facilitation of public expenditure tracking, investigations, and documentation of service delivery, and rigorous engagements with local duty bearers. The sustained operation of CBAGs at community level would offer hope and inspiration to the communities because CBAGs are usually looked upon as 'ears and eyes' of the communities [8].

However, literature review shows dearth of data on how the CBAGs sustain their activities after phase-out of donor support. Most of the studies available have concentrated on general development projects. The studies include those done in Asia [9], Latin America and parts of Sub Saharan Africa $[10,11]$. It was observed that projects experience difficulties when external support ceases [9, 11-14], resulting into wastage of human and financial resources that could have been invested effectively [15]. Since CBAGs are part of general development, it may also be implied that their continuity withers as external support ceases.

Various reasons have been offered to explain why the development projects struggle after expiry of donor support. Lungo, $\mathrm{M}$ et al pointed out that donor funded projects suffer sustainability issues due to poor community participation, low educational levels among households and undiversified household's income sources [16]. They therefore recommended that development stakeholders should allow for active participation of communities in all stages of project formulation and implementation to ensure sustainability of donor funded projects. Hofisi, $\mathrm{C}$ and Chizimba, $\mathrm{M}$ also agreed that community participation is a key determinant for the sustainability of donor funded projects [6]. Nthenge, F observed that sustainability of projects is a function of community willingness to participate in development projects, financial capacity of the project committees and adequate monitoring of the projects [17]. Okun, M observed that the financial sustainability of projects depends on the funding practices of donors [7]. He concluded that projects with easy accessibility to donor funding are most likely to be financially stable in the long run. Mugambi, M pointed out that for a donor funded project to be sustainable, it must develop a sound institutional base, a strong programmatic approach, and enough funds [18]. At the institutional level, project structures need to have established internal systems, structure, and work culture that promote strong leadership and positive organizational image and subsequently facilitate the development plans for sustainability.

Critical review of the reasons explaining the sustainability of the donor funded projects, reveal inadequate direct explanation about why CBAGs continue or discontinue to operate after cessation of donor support. The studies do not also provide the measurement unit let alone the extent to which the projects were sustainable. Moreover, most of the sustainability studies reported, were conducted immediately after the completion of the projects, which may not provide a clear picture of how the projects would be sustained after many years of no external support. It is therefore premature to conclude if the factors claimed to affect project sustainability would still hold for CBAGs after years of donor exit. Thus, the present study investigated the factors that enable CBAGs to continue operating after cessation of donor support and understand the factors that motivate the members of the CBAGs to continue anchoring the CBAGs in the absence of donor support.

\section{Literature Review}

Local government mandates local public officials to respond periodically to questions concerning how they use their authority, where the resources went, and what was achieved with them [19]. Or more simply stated, local public officials are held responsible for effective spending and performance of public funds. However, institutions of local accountability particularly the local council in Malawi are often weak, with high risk of public resources being 'captured' by local elites [20]. This is the case because local citizens are often not informed about what resources are available to their local representatives for the delivery of public services. One of the remedies to improving local government accountability is to empower CBAGs to hold local government officials accountable for their decisions 
[19].

Engagement with local governments varies from one CBAG to the other and geographical coverage of the issues being advocated for. For instance, some CBAGs are very broad in focus covering issues ranging from political, social, or economic beliefs or values such as education, health, social welfare, and food security while others are narrower and focus on specific issues with a particular target of people such as elderly, people with disability, women, and youths. This study concentrated on advocacy groups that are involved in tracking public funds in the Local Councils and fight for the welfare of the general community. Such groups advocate for local level participation in the allocation and utilization of local development resources, engage duty bearers for quality delivery of services and mobilize communities for transparency and accountability in the Local Councils.

According to Boris, E, and Mosher-Williams, R advocacy, in its most general terms, is defined as efforts used to influence policy changes [21]. For community-based activists, advocacy has become one of the most integral activities and identity. It is the vehicle that CBAGs use to bring education, awareness, and policy solutions to community issues. Therefore, Boris, E, and Mosher-Williams, R believe that the definition of community- based advocacy should be expanded to encompass the role that community-based groups play in providing a public voice that sustains local democracy [21]. Community- based advocacy offers a holistic approach that seeks to bring change to a policy, program, process, or system at local level. It seeks to request and inspire change to processes and procedures by creating an open local forum for dialogue about development issues. Community advocacy efforts increase public awareness about an issue and the community that the issue impacts. Various methods are employed by CBAGs to achieve local government accountability, including lobbying, media campaigns, publicity stunts, polls, research, and policy briefings [22]. Generally, the CBAGs make an appeal to decision makers such as Members of Parliament, Ward Councilors, Traditional leaders, and Local Council secretariat to genuinely serve the interest of the poor.

Through such efforts, CBAGs become the voice for the voiceless who may lack access to political institutions or lack knowledge about how to participate in local level decision making [23]. CBAGs provide a public voice for issues and concerns that adversely impact the poor people on the ground [21]. In many instances, the goal of a community-based advocacy is to bring about policy change that positively impacts the local community. In this study community-based advocacy is regarded as an act of influencing and inspiring changes in the Local Council through litigation, lobbying, researching, publishing, testifying, and organizing community actions facilitated by CBAGs.

The concept of community-based advocacy is becoming appealing to development partners because it makes "community participation" and "local empowerment" a reality [24]. Usually grant-makers look for dedicated and embedded local groups who are working hard to understand and address their own problems. The general principle is that people whose lives are most affected by social problems are the best judges of their strategy [25]. Therefore, development partners perceive the CBAGs as well-placed structures for community advocacy because of their proximity, both physically and socially, to local people. They are locally rooted institutions that have vital expertise in the interpersonal and caring relationships in people's everyday lives. Thus, when services are poor, violence breaks out, or a case of public funds abuse crops up, CBAGs snap into action to make sure people are served better and justly.

Because of the relevance of the community-based advocacy to the development principles and agenda of development partners, CBAGs are highly favored by development partners. While others build on already exiting CBAGs, other supporting organisations prefer to initiate and develop their own CBAGs. Largely the choice of building on existing or initiating new CBAGs are based on politics of donor visibility and need to 'fly own flag' [26]. Naming of the CBAGs also varies from one supporting organization to the others depending on the nature of the project and back donor. For instance, under DanChurchAid (DCA) programme, the CBAGs were named as Community Based Educators in Dowa and Lilongwe and, Community Action Groups in Neno and Mwanza districts (https://www.danchurchaid.org/). Oxfam in Malawi named the CBAGs as Star Circles in Karonga and Chitipa districts (https://www.oxfam.org/en/malawi), World Vision uses Citizen Voice Action in reference to CBAGs (https://www.wvi.org/malawi). This study concentrated on CBAGs that were initiated and supported by DCA from 2012 -2016 under local governance thematic area.

\section{Methodology}

The study was conducted in five (5) districts of Malawi. The districts are geographically located in Northern region (Karonga district), Central region (Dowa and Lilongwe districts) and Southern Region (Neno and Mwanza districts). The districts are among the eight districts where the local governance projects for DCA were implemented for over five-year period (2013 - 2017. Specifically, data was collected from TA Wasambo and TA Kyungu (Karonga district), TA Kayembe and Dzoole (Dowa district), TA Malili and TA Chiseka (Lilongwe district), TA Kanduku and TA Govati (Mwanza), and TA Mlauli and TA Symon (Neno district).

The study adopted a cross-sectional mixed research design. The design was adopted and considered appropriate as it allows the use of various methods to gather quantitative and qualitative data [27]. Quantitative data were collected through household interviews while qualitative data were collected using focus group discussions (FGDs), key informant interviews (KIIs), and direct observations. The quantitative data was collected using KOBO collect software - an android-based application for collecting data. The target population in this study were the members of the Community 
Based Educators, Star Circles, community activists, members from Area Development Committees, Village Development Committees and Community Action Groups that participated in the local governance projects implemented by DCA from 2013 - 2017. A total of 226 members and 16 CBAGs were interviewed. They provided information on household biodata, factors that influenced continued operation of the CBAGs as well factors that motivated them to continue patronizing the CBAGs. The qualitative data from FGDs and key informant interviews were organized and reduced through a process of coding. Through coding and content analysis the researcher was able to establish important points and facts in relation to the study objectives. Quantitative data was analysed using Statistical Package for Social Science (SPSS) software in which Logistic Regression Model (LRM) and descriptive statistics were run. Mean, median, mode and standard deviation were calculated for continuous variables and LRM was used to test for associations between categorical variables and proportions. A confidence level of $95 \%$ was used and p-values of $\leq 0.05$ was considered statistically significant.

\section{Results and Discussion}

\subsection{Demographic and Socioeconomic Characteristics of CBAG Members}

The study gathered information on household headship, education level, housing status, size of the households and income levels. This was meant to understand the private life, personal workloads, gender dimension and responsibilities of the CBAG members.

The study observed that $68.9 \%$ of the households were headed by males while $31 \%$ were led by females. As illustrated by Table 1, the average household size was 5.6 which was quite high compared to the national average of 4.4. persons per household [28].

Table 1. Demographic characteristics of the households.

\begin{tabular}{lll}
\hline Indicator & Description & Finding \\
\hline Household size & & 5.6 \\
Income level & & $\$ 213.23$ \\
& Primary & $38.5 \%$ \\
Educational level & Secondary & $59.2 \%$ \\
& Tertiary & $2.2 \%$ \\
Status of dwelling house & Permanent & $69.6 \%$ \\
& Semi-permanent & $16.5 \%$ \\
& Traditional & $7.7 \%$ \\
\hline
\end{tabular}

However, the households have relatively high average income of $\$ 213.23$ compared to average annual income of US\$100-US\$200 per year at national level [29]. In terms of educational level, over half $(59.5 \%)$ went to secondary school, $38.5 \%$ attended primary school and fewer $(2.2 \%)$ acquired tertiary education. It was also pleasing to note that $69.6 \%$ had permanent structures roofed with iron, $16.5 \%$ lived in semipermanent structure while few $(7.7 \%)$ were living in traditional houses thatched with grass.

\subsection{Enabling Factors for CBAGs After Phaseout of Donor Support}

The study assessed the key factors that affect continued operation of the CBAG as an institution at community level. Thirteen (13) factors were assessed which included marital status of respondents, responsiveness of duty bearers, availability of basic systems and procedures, unity among members, community contribution, linkages and networking, fundraising skills, availability of exit strategy, age of the respondents, sex of respondents, household headship, income level of respondents and group level advocacy.

To determine the significance and correlations of the factors that enable CBAGs to be active after phaseout of donor support, the researcher ran binary logit regression.

Table 2 presents results of the regression analysis and shows that eight variables are important enablers for a CBAG to continue operating at community level even in the absence of donor support.

Table 2. Results of logit regression model run to establish enabling factors for active $C B A G$.

\begin{tabular}{|c|c|c|c|c|}
\hline Variable & $\mathbf{X}_{\mathbf{i}}$ & Coefficient & $\begin{array}{l}\text { Std. } \\
\text { Error }\end{array}$ & Sig. \\
\hline (Constant) & & .240 & .042 & .000 \\
\hline Sex of respondent & $\mathrm{X}_{1}$ & .006 & .013 & .637 \\
\hline Age of the respondent & $\mathrm{X}_{2}$ & .001 & .000 & $.082^{* *}$ \\
\hline Marital status of respondent & $\mathrm{X}_{3}$ & .022 & .009 & $.010^{*}$ \\
\hline Household headship & $\mathrm{X}_{4}$ & .005 & .008 & .529 \\
\hline Income level of respondent & $\mathrm{X}_{5}$ & $-2.336 \mathrm{E}-008$ & .000 & .370 \\
\hline Responsiveness of duty bearer & $\mathrm{X}_{6}$ & .018 & .008 & $.034^{*}$ \\
\hline Availability of systems and procedures & $\mathrm{X}_{7}$ & -.177 & .023 & $.000^{*}$ \\
\hline Unity among members & $\mathrm{X}_{8}$ & .055 & .017 & $.001^{*}$ \\
\hline Community contribution & $\mathrm{X}_{9}$ & .222 & .022 & $.000 *$ \\
\hline Linkages and networking & $\mathrm{X}_{10}$ & .253 & .021 & $.000^{*}$ \\
\hline Group level advocacy & $\mathrm{X}_{11}$ & .009 & .008 & .298 \\
\hline Fundraising skills & $\mathrm{X}_{12}$ & .122 & .019 & $.000^{*}$ \\
\hline Availability of exit strategy & $\mathrm{X}_{13}$ & -.032 & .009 & $.001 *$ \\
\hline
\end{tabular}

* Statistically significant at $\mathrm{p}$-value $\mathrm{p}<0.05$, ** Statistically significant at $\mathrm{p}$-value $\mathrm{p}<0.1$

Marital status of respondents, responsiveness of duty bearers, unity among members, community contribution, linkage and networking, and fundraising skills were positively related to continued operation of the CBAGs. The negative correlation coefficient or association for availability of basic systems and procedures and availability of exit strategy by supporting donors meant that there is an inverse relationship between the dependent variable and the independent variables i.e., the respondents were less likely to churn for the variables with negative coefficients.

It can be interpreted that as members get aged, their attachment to the community welfare get stronger. Thus, the likelihood of continued participation in the CBAGs increases too. The study also observed that married members were more likely to continue participating in the activities that are geared towards uplifting the plight of the communities. A member who is married was perceived to be more stable in the communities compared to a youthful counterpart, thereby having more likelihood of participating in community 
development activities.

CBAGs are a form of structure which must meet minimum requirements for a basic institution. They need at least to be registered, have basic rules, systems for managing finances and leadership structure. While some CBAGs had leadership and basic rules to govern their operations, majority of the CBAGs were not registered and did not have systems and procedures for managing financial resources. This is a threat to fundraising and maintenance of donor confidence. It was not surprising that stakeholder support to the noble work of the CBAGs was minimal. In fact, at the time of the study, none of the CBAGs had any source of external funding to meet the cost of their operations.

Rights holders and advocacy groups expect their leaders to make decisions and perform their duties according to the will and wishes of the people they serve. However, the behaviour of duty bearers particularly Members of Parliament (MPs) and local councils leave a lot to be desired. CBAGs complained about the unruly behaviour of some scrupulous politicians and traditional leaders. Usually, such leaders are allegedly involved in malpractices such as abuse and misuse of public funds. To cover up their mistakes, they belittle and hate anyone who attempts to hold them accountable. Such attitudes tend to discourage some members and eventually drop out. Therefore, behaviour of the duty bearers can have greater bearing on the success and continuity of the CBAGs.

The study also observed the importance of group cohesion and solidarity in gluing members together [30]. The sharing of feelings and experiences coupled with sense of obligations and expectations help to bind members together for a common good. The effect is more pronounced when group members are geographically closer to each other. In turn this helps to strengthen the group which is essential particularly in the context of ceased donor support.

Linkages and networking are critical to the continuity of CBAGs. While networks existed among some CBAGs, the linkage was seemingly weak. Largely the networks were geographically scattered on the basis of wider cooperation. However, such pattern of network resulted into high transactional cost of meeting and interactions. Dense but segregated horizontal networks found in specific localities was considered as ideal to sustain cooperation among CBAGs.

None of the CBAGs had exit strategies to guide smooth closure of external funding. This was also confirmed by donors and implementing partners who acknowledged that exit strategies were not concretely imbedded in the design of the governance projects. However, literature on exit strategies strongly argues for the mainstreaming of exit strategies in the design and planning $[31,32]$. The absence of the exit plan was clearly felt by the CBAGs across the target districts. Many stakeholders such as community members and traditional leaders did not seem to know how to support and anchor the activities of the CBAGs after the cessation of the donor support

\subsection{Factors That Motivate CBAG Members}

The study intended to understand the key factors that motivate the CBAG members to continue pursuing advocacy activities in their respective sites. Seven factors were assessed which included wanting to belong to a group, quest of members to curb corruption, naturalness of members to defend the rights of others, need for learning and sharing, increased prevalence of community problems, expectations for future benefits and respect for community trust.

Analytically, a binary logit regression was ran to establish the significance and correlations of the factors that motivated community members to continue participating in the $\mathrm{CBAG}$ advocacy activities after phaseout of donor support.

The results of the regression analysis show that three out of seven variables significantly motivated the CBAG members to continue participating in the advocacy activities after donor support (Table 3 ).

Need to end corruption, increased prevalence of community problems and expectation for future benefits were significant at $\mathrm{p}<0.05$. This implies that need to end corruption, increased prevalence of community problems and expectation for future benefits were essential in motivating the respondents to remain participating in the $\mathrm{CBAG}$ activities. Peer pressure, natural human rights defender, learning and sharing and community trust were negatively related to continued participation of the respondents in CBAGs activities.

Table 3. Results of logit regression model run to establish motivating factors.

\begin{tabular}{lllll}
\hline Variable & X & Coefficient & S. E. & Sig. \\
\hline Wanting to belong and peer pressure & X1 & -.348 & .423 & .411 \\
Need to end corruption & X2 & 1.962 & .534 & $.000^{*}$ \\
Moved by empathy and fulfilment & X3 & -.089 & .494 & .857 \\
Learning and sharing & X4 & -.438 & .513 & .393 \\
Community problems & X5 & .932 & .417 & $.025^{*}$ \\
Financial, material, and & $\mathrm{X} 6$ & .913 & .415 & $.028^{*}$ \\
non-material benefits & & & .504 & .969 \\
Community trust & X7 & -.020 & .913 & .095 \\
Constant & & -1.522 & .9 &
\end{tabular}

* Statistically significant at p-value $\mathrm{p}<0.05$

The negative correlation coefficient or association means that there is an inverse relationship between the dependent variable and the independent variables i.e., the respondents were less likely to churn for the variables with negative coefficients.

It can be interpreted that the active involvement of members in the advocacy work of the CBAGs was driven by the rampant corruption and abuse of public finances in their respective local councils. Members felt duty bound to engage the local councils in protecting the public purse and improve service delivery. There were reportedly many cases that were cited by the respondents, where the local councils had allegedly mismanaged local development resources which justified their drive to continuously participate in the grassroot advocacy work.

The study noted the existence of various development challenges across the five districts, which included $75.7 \%$ of the households being food insecure and 52.4\% living below the poverty levels. Such community challenges might have 
also pushed the members to take active role in advocating for better service delivery in their respective districts. The members were of the view that their continued engagement with duty bearers would help to address problems rocking up their communities.

On the other hand, the study noted that some members (63.2\%) of the CBAGs continued to participate in the advocacy activities on anticipation of future benefits. While they enlisted as members of the CBAGs on the basis of voluntarism, the reality is that they wanted the financial, material, and non-material benefits that come along the donor funded projects such as T- shirts, training skills, participation allowances. Similar observations were made by Kilewo, G and Frumence, G [33] and Goodman, R et al [34].

\section{Conclusion}

CBAGs are essential structures preferred by donors and development partners in advancing citizen engagement with duty bearers at local level. However, their continuity is not guaranteed after phasing out of donor support. The study has revealed that there are both enabling and motivating factors that are critical for continued operations of the CABGs in the communities. Insightful analysis of the factors is paramount for continued citizen action and good local governance in general.

\section{Recommendations}

For CBAGs to continue operating after donor support, implementing organisations together with members of the CBAGs should make it a must for projects working with CBAGs to have exit strategies. The exit strategy would help to concretize the phasing out plan for the community initiatives. It would also help the stakeholders to clearly understand and execute their roles in the context of ceased donor support. Donors and well-wishers should also consider investing in the weak institutional areas of the CBAGs such as organization registration, fundraising and organization systems and procedures. This would help to strengthen the institutional nature of the CBAGs, which is an essential prerequisite for their continued functionality and operation. CBAGs should also have properly established linkages with key stakeholders including traditional leaders, other CBAGs, and district CSO forum. The coalition of community CSOs with support from traditional leaders and district CSO forum would help to attain unity of purpose in the local advocacy agenda. The district CSO forum would also provide technical support and strategic direction to the CBAGs for effective advocacy at local level. Supporting organisations should design integrated advocacy interventions that achieve advocacy agenda without compromising the personal needs of the CBAGs members. They need to support the CBAG members with livelihoods activities which will offer immediate needs as they pursue advocacy work.

\section{Acknowledgements}

This thesis could not have been completed without the invaluable support that I received from so many people over the years. It is a rare opportunity and my wish to offer my utmost sincere thanks to the following people.

Firstly, I would like to express my heartfelt gratitude to my family (wife and children), supervisors and tutors from Atlantic International University and Lilongwe University of Natural Resources and Agriculture for their patience, motivation, and continuous support. Their guidance and moral support helped me to clearly shape up the research design and writing of the thesis. I would also like to thank my employer DanChurchAid (DCA) for the financial support and time to study while working. I will not forget the technical and social support which my workmates at DCA provided in the course of the study.

Great appreciation is extended to the rural right holders, Community Based Educators (CBE), Area Development Committees (ADC) and star circles who spared their time to respond to the questionnaires. Local council members, projects committees' members, project stakeholders and traditional leaders across the four districts of Karonga, Lilongwe, Dowa, Mwaza and Neno where the study was conducted.

For those not mentioned or forgotten in the list I apologize. Deeply in my heart I say thank you as well.

\section{References}

[1] Leroux K and Carr J., (2007). Explaining Local Government Cooperation on Public Works: Evidence From Michigan. https://doi.org/10.1177/1087724X07302586.

[2] CIVICUS. (2018). State of Civil Society Report 2018. Year in Review: Top Ten Trends. Retrieved from https://www.civicus.org/documents/reports-and-publications/S OCS/2018/socs-2018-overview_top-ten-trends.pdf.

[3] Grimsley S, 2017. Advocacy Groups: Definition \& Examples. Retrieved from https://study.com/academy/lesson/advocacy-groups-definition -examples.html.

[4] GoM. (2017). Malawi Decentralisation Policy, 1998 rev 2017. Ministry of Local Government and Rural Development. Government Press.

[5] GoM. (2010). Local Government Act, 2010, Act No 17 of 2010. Ministry of Local Government and Rural Development. Government Press.

[6] Hofisi, C and Chizimba, M, (2013). The Sustainability of Donor Funded Projects in Malawi. 10.5901/mjss.2013.v4n6p705. Mediterranean Journal of Social Sciences.

[7] Okun, M. (2009). Factors affecting the sustainability of donors funded projects in arid and semi-arid areas in Kenya: A case of Marsabit Central District. A Research project submitted in partial fulfilment of the requirement for the degree of Master of Business Administration, School of Business, Kenyatta University.

[ir-library.ku.ac.ke/bitstream/123456789/3494/3/Okun+Marti n+Adera.pdf] site visited on 20 February 2017. 
[8] Chiweza A, (2015). Power to the People: A Guide for Public Expenditure Tracking for Local Governments. www.odi.org.

[9] ADB, (2010). Special Evaluation Study on Post - Completion Sustainability of Asian Development Bank Assisted Projects. Asian Development Bank Independent Evaluation Department. [http://www.oecd.org/derec/adb/47186868.pdf]. Site visited on $13 / 7 / 2013$.

[10] IFAD, (2007). United Republic of Tanzania: Participatory Irrigation Development Programme (PIDP), Completion Evaluation, International Fund for Agricultural Development (IFAD) 46pp. [https://www.ifad.org/evaluation/ reports/ppa/tags/ tanzania/1086/1860133] site visited on 13 July 2014.

[11] World Bank, (2012). The World Bank Annual Report 2012: Volume 1. Main Report. World Bank Annual Report. Washington, D.C. 68 pp.

[12] Kamau, G. B. (2014). Factors influencing successful implementation of community-based projects: A Case of Food Security Projects in Kiambu County. A research report submitted in partial fulfilment of the requirements for the award of a degree in Master of Arts in Project Planning and Management of the University of Nairobi. 2014.

[13] Oino, P. G., Towett, G., Kirui, K. K. and Luvega, C. (2015). The dilemma in sustainability of community-based projects in Kenya, Global Journal of Advanced Research 2 (4): 757-768. [gjar.org/publishpaper/vol2issue4/d177r18.pdf] site visited on 17 June 2016.

[14] World Bank, (2005). The effectiveness of World Bank Support for Community-based and Driven Development: An OED Evaluation. 199pp.

[15] Savaya, R., Elsworth, G. and Rogers, P. (2009). Projected sustainability of innovative social programs. Evaluation Review 33 (2): 189-205. [http://erx.sagepub.com]. Published 2014. Corpus ID: 130800457.

[16] Lungo M, Mavole J and Martin O (2017) Determinants of Project Sustainability beyond Donor Support: Case of Caritas Norway Supported Governance Project in Mansa Diocese, Zambia. Arts Social Sci J 8: 278. doi: 10.4172/2151-6200.1000278.

[17] Nthenge F, (2014). Factors influencing sustainability of donor funded projects: a case of Wenje water projects in Tana river.

[18] Mugambi M, (2016). Donor funding practices and financial sustainability of donor aided projects in world vision Kenya. University of Nairobi, Kenya.

[19] Amosa D, (2010). Local government and good governance: The case of Samoa. School of Management and Public Administration University of the South Pacific. http://epress.lib.uts.edu.au/ojs/index.php/cjlg.

[20] O'Neil T, and Cammack D,. (2014). Fragmented governance and local service delivery in Malawi. Shaping policy for development. www.odi.org.
[21] Boris, E, and R Mosher-Williams. (1998). "Nonprofit Advocacy Organizations: Assessing the Definitions, Classifications, and Data." Nonprofit and Voluntary Sector Quarterly 27 (December): 488-506.

[22] Delibashzade R,. (2016). The Role of Interest Groups: Best Practices, Case Studies, and Lessons Learned. DOI: 10.13140/RG.2.1.2086.8247.

[23] Chasukwa M, Chiweza A and Chikapa-Jamali M,. (2013). Public Participation in Local Councils in Malawi in the Absence of Local Elected Representatives-Political Eliticism or Pluralism? DO - 10.1177/0021909613509218. Journal of Asian and African Studies.

[24] Kamruzzaman, P, White, S, (2018). Empowerment and Community Participation. 10.1002/9781118924396.wbiea2062.

[25] Lentfer J, (2015). Five reasons funding should go directly to local NGOs. International Development Exchange. https://www.theguardian.com/global-development-professiona ls-network/2015/nov/13/.

[26] Bourguignon, F and Platteau, J, (2014). The Hard Challenge of Aid Coordination. 10.1016/j.worlddev.2013.12.011.

[27] Kothari, C. R. (2004). Research Methodology: Methods and Techniques. 2nd Edition, New Age International Publishers, New Delhi.

[28] NSO, (2016). Malawi Demographic Household Survey, Government of Malawi.

[29] World Bank, (2019). Factsheet for Malawi. World Bank Group. www.worldbank.org.

[30] Marin, M. (2018). A Moral Theory of Solidarity. By Avery Kolers. Oxford: Oxford University Press, 2016. 208p. $\$ 80.00$ cloth. Perspectives on Politics, 16 (3), 802-803. doi: $10.1017 / \mathrm{S} 1537592718001603$.

[31] Levinger, B and McLeod, J. (2002). Hello, I Must Be Going: Ensuring Quality Services and Sustainable Benefits through Well-Designed Exit Strategies. Education Development Center, Inc. Center for Organizational Learning and Development (COLAD), 55 Chapel Street Newton, MA 02458. 24pp.

[32] Davis, N. and Sankar, M., (2006). A Practice Review of UNESCO $s$ Exit and Transition Strategies. [http://unesdoc.unesco.org/images/0014/001494/149459e.pdf]. Site visited on 30.3.2011.

[33] Kilewo G and Frumence G, (2015). Factors that hinder community participation in developing and implementing comprehensive council health plans in Manyoni District, Tanzania. Glob Health Action. 2015; 8: 10.3402/gha.v8.26461.

[34] Goodman, R. M., Speers, M. A., McLeroy, K., Fawcett, S., Kegler, M., Parker, E., Wallerstein, N. (1998) "Identifying and defining the dimensions of community capacity to provide a basis for measurement. Health Education \& Behavior, 25 (3): 258-278. 